\title{
Pedro de Ribadeneyra escribe a Claudio Aquaviva Un episodio de la polémica jesuita sobre los estatutos de pureza de sangre
}

\author{
Mario PRADES VILAR
}

\begin{abstract}
RESUMEN
Uno de los fenómenos característicos de la sociedad española, a partir del año simbólico de 1492, es la progresiva adopción de los estatutos de pureza de sangre por parte de diversas administraciones. La Compañía de Jesús, sin embargo, se negó durante casi todo el siglo XVI a aplicar estos estatutos, alegando para ello la voluntad expresada en tal sentido por el mismo Ignacio de Loyola. Sin embargo, en 1593 la Quinta Congregación General decide implantar el examen de pureza para el ingreso en los Colegios de la Compañía. Este artículo describe la tenaz oposición que contra esta decisión realizó el jesuita español Pedro de Ribadeneyra, de origen judío, en una serie de cartas dirigidas al entonces General, Claudio Aquaviva. Asimismo, contextualiza la polémica jesuita en torno a los estatutos de pureza de sangre dentro del giro que la Compañía realiza tras el ascenso al generalato de Everardo Mercuriano y, después, con Aquaviva, y cuya principal característica es el alejamiento de los conversos de los puestos de poder.
\end{abstract}

PALABRAS CLAVE: España, Compañia de Jesús, estatutos de pureza de sangre, cultura conversa, Pedro de Ribadeneyra, Everardo Mercuriano, Claudio Aquaviva, revuelta de los memorialistas

\begin{abstract}
One characteristic feature of Spanish society, from the symbolic year 1492, is the progressive adoption of the purity-of-blood laws by various administrations. The Society of Jesus, however, declined during most of the sixteenth century to apply these statutes, claiming to do the will expressed in this regard by Ignatius of Loyola himself. However, in 1593 the Fifth General Congregation decided to implement the purity test for the admission to the Colleges of the Company. This article describes the tenacious opposition against this decision made by the Spanish Jesuit Pedro de Ribadeneyra, of Jewish origin, in his letters to the then General, Claudio Aquaviva. Also contextualizes Jesuit controversy around statutes of purity of blood within the profound change the Company suffered after the rise to generalship of Everard Mercurian and then with Aquaviva, and whose main characteristic is the removal of the converso jesuits from the Italian directive positions.
\end{abstract}

KEYWORDS: Spain, Society of Jesus, purity-of-bood laws, converso culture, Pedro de Ribadeneyra, Everard Mercurian, Claudio Aquaviva, memorialistas revolt

Este artículo aborda la polémica en torno a la aplicación de los estatutos de pureza de sangre dentro de la Compañía de Jesús, sucedida a caballo entre los siglos XVI y XVII. Se trata de una polémica lejana en el tiempo respecto la Reconquista española; sin embargo, se encuentra muy cerca de lo que esa reconquista representó en términos ideológicos, sociales y culturales. Dicha polémica se inscribe, de hecho, en un horizonte histórico iniciado con la persecución a los judíos, que culminaría con su expulsión en 1492, y con la aparición de una minoría conversa sobre cuya sinceridad religiosa «investigaría» la Inquisición con los métodos que conocemos. También se inscribe en este horizonte el ideal de una sociedad de castellanos viejos y de una monarquía eminentemente católica, 
que hace de la religión una de sus señas fundamentales de identidad y justifica con ella las guerras emprendidas por el monarca fuera de las fronteras de su reino, en la medida en que estos elementos se encuentran muy presentes en la idea de sociedad castellana legada por el reinado de los Reyes Católicos. Ilustraré primero, de manera sumaria, esta idea para tratar después la cuestión de la posición de la Compañía respecto los estatutos de pureza de sangre.

1. El 12 de Octubre de 1504, ante la inminencia de su muerte (que la alcanzaría al mes siguiente), la reina Isabel I de Castilla firma el testamento donde ha dispuesto sus últimas voluntades. En dicho documento la reina católica nombra heredera universal de sus reinos a su hija primogénita, la princesa Juana, junto a su marido Felipe «el Hermoso», duque de Borgoña. A amnos les encomienda que «como Católicos Príncipes, tengan mucho cuidado de las cosas de la honra de Dios, y de su santa Fe», así como

«que sean muy obedientes a los Mandamientos de la Madre Santa Iglesia, y protectores, y defensores de ella como son obligados, y que no cesen de la conquista de África, y de puñar por la Fe contra los infieles; y que siempre favorezcan mucho las cosas de la Santa Inquisición contra la herética pravedad» ${ }^{1}$.

Esta breve exhortación contiene tres ideas fundamentales: la primera es que los reyes de Castilla deben ser cristianos católicos, obedecer por tanto los mandatos de la Iglesia y defenderla ante ataques de posibles enemigos exteriores tales como, por ejemplo, el Gran Turco, cuya amenaza incumbía desde las costas del norte de África. En principio, instar al monarca a atenerse a los principios de la moral católica y a defenderlos con la espada en caso de necesidad no supone ninguna novedad: la guerra defensiva era considerada justa por la tradición católica, tal como la teoriza San Agustín o, posteriormente, Santo Tomás, y no despertaba problemas de conciencia en ningún monarca cristiano.

La segunda idea, sin embargo, va un paso más allá de la guerra defensiva: «que no cesen de la conquista de África, y de puñar por la Fe contra los infieles». Isabel exhorta a su hija y yerno a proseguir con la conquista de África y, por tanto, luchar contra los

1 Cit. en F. DÍAZ-PLAJA (ed.), La historia de España en sus documentos. El siglo ХИ. Madrid, Instituto de Estudios Políticos, 1958, 38. 
enemigos de la fe católica fuera de sus reinos. Con esto se justifica religiosamente una guerra ofensiva: el monarca español no debe limitarse a empuñar la espada para defender su territorio, sino que debe también hacer la guerra para extenderlo, motivado por un ideal de propagación de la fe católica en los territorios tradicionalmente musulmanes. En el fondo, Isabel está prolongando esa peculiar cruzada que, bajo el nombre de Reconquista ${ }^{2}$, había empeñado a los españoles durante casi ocho siglos, siendo su último capítulo la rendición de Granada en 1492 a instancias suyas. La Reina Católica recurre, así, a la idea de la Reconquista para legitimar la extensión de la guerra peninsular al norte de África. La idea de una «Conquista» propiamente dicha, que debía continuar idealmente la Reconquista española, está muy presente en la concepción política y religiosa de los Reyes Católicos. El hecho de que Isabel dispusiera en su testamento ser enterrada en la capital del nuevo reino de Granada encierra una carga simbólica evidente, y nos revela la importancia y el significado que para ella tenía esa última conquista.

Tras la muerte de Isabel, será el Cardenal Francisco Jiménez de Cisneros quien promoverá con mayor entusiasmo las campañas castellanas en el norte de África, en las que se toman las costas de Mazalquivir en 1505, el Peñon de Vélez en 1508 y Orán en 1509. Seguiría la toma de Bujía y de Trípoli y la sumisión de Argel (1510-1511). Estas conquistas participan, sin duda, del antiguo espíritu de la cruzada, sentido con fervor por muchos súbditos de la Corona, pero es poco probable que Fernando el Católico pensara seriamente en extender sus campañas norteafricanas hasta Jerusalén. A pesar de las visiones de la beata de Piedrahita, según las cuales Fernando «no moriría antes de ganar Jerusalén» ${ }^{3}$, el Católico era hombre de aguda inteligencia política, y sabía perfectamente que lo más conveniente era afianzar sus dominios en el Mediterráneo occidental: su objetivo era sólo el norte de África, territorio que, junto a Nápoles -ganado a Luís XII en 1504-, se unía al resto de reinos mediterráneos de la corona de Aragón, formándose así un sólido bloque territorial donde afianzar un poder hegemónico. La cruzada quedaba circunscrita al ámbito de la expansión territorial castellano-aragonesa. De este modo, a los ideales espirituales y religiosos de la cruzada Fernando aunaba, de manera harto

2 Soy consciente de que términos como «reconquista»y «cruzada» encierran realidades cambiantes, complejas y muy distintas una de otra. Dado que ninguno de los dos términos supone el tema central de este artículo, voy a utilizarlos conjuntamente para denotar, más que las realidades que representan, el ideal político, religioso y militar con que los Reyes Católicos (Isabel en este caso) colorean ambos términos.

3 Cit. en H. KAMEN, Una sociedad conflictiva: España, 1469-1714. Madrid, Alianza, 1995, 32. 
pragmática, los intereses estratégicos de su política exterior, hecho que Maquiavelo apreciaría en su momento ${ }^{4}$. Sin embargo, independientemente de la fe de Fernando en la posibilidad real de extender el ideal de Cruzada hasta Jerusalén, interesa destacar aquí que la belicosidad de una guerra ofensiva queda, con la admonición de Isabel, íntimamente ligada a la confesión del catolicismo, en la medida en que esta religión justifica aquella guerra.

La tercera idea contenida en el testamento de la Reina Católica es la necesidad, vivamente sentida y comunicada por la reina a sus sucesores, de favorecer «las cosas de la Santa Inquisición»y, en general, combatir la herejía. El enemigo de la fe se encuentra no sólo en las costas de África, sino también dentro de las fronteras del reino, y urge combatirlo con el arma inquisitorial. ¿Pero a quién se refiere Isabel cuando habla de «herejes»? En principio, como es sabido, a los falsos conversos cuyo control y represión fue el motivo de la creación de la Inquisición española en 1478. Este hecho constituyó un episodio crucial dentro de la historia de las tensiones entre cristianos viejos y cristianos nuevos que, desde hacia muchos años, habían estado a la orden del día en no pocos municipios castellanos, y se sumaban al ya antiguo conflicto entre judíos y cristianos. Dicho conflicto culminaría con el famoso edicto, promulgado por Isabel y Fernando el 31 de Marzo de 1492, por el que se daba a los judíos un plazo de cuatro meses para bautizarse o abandonar los reinos de los Reyes Católicos. A la famosa expulsión de los judíos se acompañaba la feroz persecución de los conversos por parte de la Inquisición, comandada desde 1483 por el no menos famoso Tomás de Torquemada, y que, según el cronista Hernando del Pulgar, en 1490 ya había quemado a 2000 personas en la hoguera y «reconciliado» a $15000^{5}$.

Sin embargo, la herejía «judaizante», motivo originario de constitución de la Inquisición española (en cuanto institución autónoma y dependiente directamente del monarca), fue sólo la primera de las muchas corrientes espirituales que serían perseguidas durante todo el siglo XVI: moriscos, alumbrados, protestantes, erasmistas, e incluso

4 En el capítulo XXI de El Príncipe leemos el famoso pasaje sobre Fernando de Aragón, príncipe nuevo que, en la conquista de Granada «possé nutrire (con denari della Chiesa e degli populi) exerciti e fare uno fondamento con quella guerra lunga alla milizia sua». Además de esto, «servendosi sempre della religione, si volse ad una pietosa crudeltà, cacciando e spogliando el suo regno de marrani», y luego «assaltò sotto questo medesimo mantello l'Africa» (N. MACHIAVELLI, Le grandi opere politiche, I. Il Principe, Dell'arte della guerra, ed. de Gian Mario Anselmi y Carlo Varotti. Turín, Bollati Boringhieri, 1992, 122).

5 Cfr. H. KAMEN, Una sociedad conflictiva, 79. 
miembros destacados de la Iglesia española, como Bartolomé de Carranza o fray Luis de León, estuvieron en el punto de mira de algunos de los inquisidores generales.

La aplicación del término «hereje» a más y más corrientes espirituales con el paso del tiempo respondía a la perfección a la observación lúcidamente realizada por Erasmo en su Utilissima consultatio de bello Turcis inferendo, publicada en 1530 a propósito de la guerra de Carlos V contra el Turco: la intolerancia -recuerda el gran humanista-, al igual que la justificación religiosa de la violencia, no se limita al objetivo del momento; por su misma naturaleza, tiende a difundirse como una enfermedad en el cuerpo de la sociedad que la admite en su seno: «cuando empieza a pensarse que se debe hacer la guerra para conquistar el paraíso la violencia no conoce límites. Se encienden las hogueras contra los herejes y empiezan a considerarse tales incluso los hebreos bautizados a la fuerza que regresan a su religión». Era, esta última, una clara alusión a las hogueras de la Inquisición española en las que ardían los «marranos» ${ }^{6}$. Desde que la Inquisición se afianza como instrumento de control doctrinal al servicio del poder, cualquier desviación de la ortodoxia se vuelve objeto de sospecha y persecución; y las desviaciones serían numerosas, dado que eran los mismos inquisidores quienes fijaban, de vez en vez, los límites de dicha ortodoxia.

Así pues, en el testamento de la reina Isabel queda claramente establecida la necesidad no sólo de defender los reinos españoles de la amenaza turca, sino de atacar a los enemigos de la fe, ya sean éstos los infieles musulmanes fuera de las fronteras del reino, ya sean los herejes que amenazan la profesión de la verdadera fe desde dentro. Los instrumentos elaborados por los Reyes Católicos para tal fin son dos: por un lado, la extensión del ideal de cruzada, concretamente del mito de la Reconquista, una vez tomada Granada, fuera de las fronteras españolas. Esto llevaría, con el paso del tiempo, a la justificación religiosa de las guerras que la monarquía española emprendería en el futuro contra luteranos, calvinistas y anglicanos. Por otro, la creación de una Inquisición española que, de manera autónoma respecto el resto de instituciones y poderes sociales (pero dependiente de la voluntad del monarca), perseguirá celosamente cualquier atisbo de herejía dentro de España. La Inquisición perpetuará la persecución de herejes una vez

6 Cfr. A. PROSPERI, «'Guerra giusta' e cristianità divisa tra Cinquecento e Seicento», en M. FRANZINELLI Y R. BOTTONI (eds.), Chiesa e guerra. Dalla 'benedizione delle armi' alla 'Pacem in terris'. Bolonia, Il Mulino, 2005, 62. 
extinguida la «amenaza» conversa, de la misma manera que el ideal de la Reconquista se perpetuará en las guerras de religión que empeñarán a los Austrias mayores durante todo el siglo XVI. El ideal de la cruzada, de la guerra santa contra el infiel, servirá para justificar, entrado el siglo, tanto las guerras contra las Iglesias protestantes como la guerra de ocupación de las colonias americanas, esto es, la «conquista» de América.

Si nos preguntamos sobre las intenciones de Isabel y Fernando a la hora de propagar este tipo de ideales, creo que podría decirse que los Reyes Católicos no buscaron, de manera explícita, una homogeneidad religiosa en España, sino más bien el control político y el consenso popular que dicha homogeneidad proporcionaba. Aún así, con los Reyes Católicos moría la España de la convivencia entre las tres grandes religiones (convivencia conflictiva, sin duda, y problemática) y empezaba a generarse un consenso popular en torno a una concepción del catolicismo que perdía en tolerancia cuanto ganaba en beligerancia y propensión a la justificación de la violencia. En este contexto, la acción de la Compañía de Jesús parece ir en contra de los ideales político-religiosos dominantes y las directivas disciplinarias impuestas por la Inquisición. Ilustraremos la actitud de la Compañía hacia una de estas directivas: la imposición de los estatutos de limpieza de sangre.

2. Es sabido que Ignacio de Loyola siempre se negó a aplicar los estatutos de pureza de sangre en el ingreso a los Colegios de la Compañía, a pesar de las presiones que recibió desde numerosas esferas. Esto le valió a la Compañía no pocos problemas en tierras castellanas, comenzando con la enemistad que se ganó con el famoso arzobispo Juan Martínez Silíceo, principal promotor del establecimiento de los estatutos en Castilla desde que los impusiera en el cabildo de la catedral de Toledo en 1547. Silíceo de manera explícita se declaró enemigo de la Compañía por la negativa de Loyola a aplicar los estatutos.

Un aspecto de este desencuentro tiene que ver con la lucha por el poder jurisdiccional que presidió el conflicto de los jesuitas con la Inquisición española durante toda la segunda mitad del siglo XVI. La Compañía se atenía a las prerrogativas concedidas por el Papa, y por tanto al derecho que les asistía desde la sede vaticana en su manera de proceder, mientras que la Inquisición encarnaba la potestad de la corona española, pretendidamente superior a la papal en los territorios castellanos. Los Austrias mayores 
tendían, en este sentido, a sospechar de una Compañía que actuaba independientemente de la jurisdicción y el control monárquicos. La negativa a aplicar los estatutos, contra lo que era la norma general en las instituciones castellanas, era uno de los muchos casos que reflejaban este conflicto de poderes ${ }^{7}$.

Ahora bien, a este conflicto jurisdiccional hay que sumar las profundas convicciones espirituales de Ignacio de Loyola: el fundador de la Compañía no sólo no abrigaba prejuicios contra los judíos, sino que consideraba al descendiente de judíos destinatario de una gracia especial, por «ser el hombre pariente de Christo N. S. secundum carnem, y de nuestra Señora la gloriosa Virgen María» ${ }^{8}$ A pesar de la prolongadas disensiones internas en la Compañía en torno al tema y la continua insistencia de Antonio Araoz, primer provincial jesuita en Toledo, para que se prohibiera la entrada a conversos, los Estatutos de la Compañía no negaban el ingreso a las personas de extracción judía9 . El criterio para la aceptación en la orden de un nuevo candidato siempre fue el de sus cualidades personales, independientemente de su origen socio-religioso, pues lo que importaba no era tanto la proveniencia cuanto la dirección futura: trabajar para el fin apostólico y de conversión universal que se había impuesto la Compañía.

Hay que señalar que esta actitud de Loyola resulta plenamente consecuente con su concepción misma de la Compañía como instrumento al servicio de Dios, cuyo fin último consiste en dar a luz a un nuevo tipo de hombre religioso, un «cristiano nuevo», distinto del presente en el resto de las órdenes religiosas, que se guía por un nuevo ideal evangelizador más acorde con su tiempo. Este ideal se traduce en la creación de misioneros capaces de adaptarse a todas las situaciones sociales, culturales y mentales (gracias al proceso de accomodatio jesuita) para lograr el fin último de Compañía: la extensión universal del cristianismo. Por tanto, el jesuita se presenta dentro de la tradición

7 Es un desencuentro conocido. Algunos datos recientes en I. IANUZZI, «Mentalidad inquisitorial y jesuitas: el enfrentamiento entre el cardenal Silíceo y la Compañía de Jesús», en Cuadernos de Historia Moderna, 24, 2000, 11-31.

8 Cit. en C. O'NEILL Y J. M. DOMÍNGUEZ (eds.), Diccionario Histórico de la Compañia de Jesús, t. II. Madrid, Universidad Pontificia Comillas, 2003, 1003.

9 Araoz representa a cierto grupo de jesuitas españoles que contaba con poderosos contactos en la corte real, concretamente con el grupo de nobles liderado por el príncipe de Éboli, Ruy Gómez de Silva (la conocida «facción ebolista»). Este grupo no veía con buenos ojos la permisividad de la Compañía para con los nuevos cristianos, tal como el mismo príncipe hizo saber a Ignacio expresamente. Loyola, sin embargo, nunca cedió a las presiones provenientes de España, tanto de los Colegios provinciales como de la misma corte del rey Felipe. Tampoco lo haría la Compañía, como lo muestra la elección de Diego Laínez como nuevo General de la Compañía tras la muerte de Ignacio, que no sentaría nada bien en el grupo ebolista dada la ascendencia judía del nuevo General. 
eclesiástica como hombre nuevo, el primero en intentar un proceso de aculturación que lleve a una conversión eficaz de herejes y gentiles. Como dirá Jerónimo Nadal: «vetus homo cum suis actibus exuendus, novus, et ille quidem in Societate, religiosus induendus est» ${ }^{10}$. Este ideal de nuevo religioso, por definición, poco podía compartir con la jerarquía social y las distinciones de grupo propias de una sociedad de cristianos viejos, para la cual los estatutos de pureza de sangre eran una norma constitutiva. Por contra, era normal que el ideal de nuevo religioso promulgado por los jesuitas atrayera a los «cristianos nuevos», esto es, a los cristianos conversos tan presentes en la sociedad castellana del siglo XVI. De este modo el «cristiano nuevo», menospreciado por los estamentos más tradicionalistas, se convertía en el candidato perfecto para convertirse en el «hombre nuevo» promulgado por la literatura jesuita fundacional.

La idea de la novedad en la forma de apostolado, en la manera de ser religioso, en las convicciones íntimas, y la manera en que ésta se refleja en la sociedad, acercan a los primeros jesuitas a un tipo de espiritualidad propio de ambientes conversos, que se materializaría en creencias de corte alumbrado y erasmista. Es conocido que Loyola, durante su estancia en Salamanca, tuvo problemas con la Inquisición debido a las sospechas que levantaba la novedad de su práctica religiosa: su predicación, sus ejercicios espirituales, su examen de conciencia. También sabemos que durante esta etapa temprana de su trayectoria religiosa estuvo en contacto con grupos erasmistas y con el ambiente espiritual converso. Bataillon, por ejemplo, ha llamado la atención sobre la figura de Maeso Miona, confesor de Loyola en Alcalá. Era Miona un iluminado vinculado al grupo erasmista de Bernardino Tovar, hermano del Juan de Vergara procesado más tarde por la Inquisición cuando iniciaron las persecuciones antierasmistas y antiluteranas ${ }^{11}$. Miona fue quien aconsejó a Ignacio que leyera el Enchiridion militis christiani de Erasmo, acercándole a

10 Cit. en G. IMBRUGLIA, «Ideali di civilizzazione: la Compagnia di Gesù e le missioni (1550-1600)», en A. PROSPERI y W. REINHARD, (eds.), Il Nuovo Mondo nella coscienza italiana e tedesca del Cinquecento. Bolonia, Il Mulino, 1992, 288.

11 El nombre de Miona aparece varias veces en la deposición de un testigo del proceso de Vergara, el sacerdote Diego Hernández, quien muestra además conocer bien el ambiente de Alcalá por el que se movían los iñiguistas en aquella época, en torno a 1530 (cfr. M. BATAILLON, «De Erasmo a la Compañía de Jesús», en ID., Erasmo y el erasmismo, Barcelona, Crítica, 2000, 215). Sobre las relaciones de Loyola con Erasmo es interesante, además de la obra de Bataillon, J. W. O'MALLEY, «Renaissance humanism and the first jesuits», en J. PLAZAOLA (ed.), Ignacio de Loyola y su tiempo, Congreso internacional de historia (9-13 Septiembre 1991). Bilbao, Mensajero, 1992, 381-403 y, desde el punto de vista de su influencia en el sistema pedagógico jesuita, el artículo de M. FOIS incluido en ese mismo volumen: «La giustificazione cristiana degli studi umanistici da parte di Ignazio di Loyola e le sue conseguenze nei gesuiti posteriori», 405-440. 
la nueva espiritualidad reformista del pensador holandés. Si bien Ignacio mostró ciertas reservas hacia la obra, para Bataillon es indudable que su espíritu confirmó a Loyola en su original vocación, así como en la legitimidad de la innovadora forma de apostolado que estaba a punto de alumbrar. La estrecha relación que, desde este momento, uniría a Loyola con su antiguo confesor evidencia, por otra parte, la afinidad entre la espiritualidad jesuita y la propia de ambientes conversos castellanos ${ }^{12}$.

De este modo se entiende que la Compañía de Jesús fuera, desde sus inicios, reacia a la aplicación de los estatutos de pureza de sangre. Parece, de hecho, que nada podía ser más contrario al sentir de Ignacio de Loyola, y sus inmediatos sucesores seguirían la misma línea de pensamiento durante casi todo el siglo XVI. Sin embargo, la Compañía acabaría aplicando los estatutos en sus Colegios en 1593. Los motivos de este cambio no quedan del todo claros: puede verse como una concesión a los intereses de Felipe II, o como el resultado de una importante revolución en los vértices de la Compañía.

3. La actitud de la Compañía hacia los conversos empieza a cambiar con el inicio de la «fase italiana» en el generalato de la misma. En la década de los ochenta, una vez concluida la llamada «revuelta de los memorialistas» y finiquitado el conflicto con Felipe II ${ }^{13}$, Claudio Aquaviva, quinto General de la Compañía, endurecerá la política de admisión en los Colegios teniendo en cuenta, como ya hiciera Everardo Mercuriano antes que él, la

12 M. BATAILLON, «De Erasmo a la Compañía de Jesús», 222 y ss., advierte otro acercamiento al espíritu erasmista en la primera reunión de los jesuitas fundadores, en Roma en 1539, para definir las reglas de la Compañía. No parece casual que por entonces buscaran la protección de cardenales erasmistas como Pole y Contarini, ligados al conocido grupo valdesiano activo en Roma por aquella época en torno a Victoria Colonna. Ciertos pasajes de las primeras reglas de la Compañía, de intención antimonástica y por tanto protoluteranos, tuvieron que ser eliminados para lograr la aprobación final de la Compañía por parte de Paulo III.

$13 \mathrm{La}$ «revuelta» o «crisis de los memorialistas» siguió al «exilio forzado» de numerosos jesuitas españoles residentes en Italia tras el ascenso al generalato de la Compañía de Everardo Mercuriano en 1572. Se trata del primer General no español de la Compañía, y su elección obedece a una serie de maniobras orquestadas por el Papa Gregorio XIII para evitar la elección del que parecía el candidato más probable a ocupar el cargo: el padre Juan de Polanco (secretario personal de Ignacio de Loyola). Tras el ascenso de Mercuriano numerosos jesuitas españoles se ven alejados de los puestos de poder de la Compañía para realizar tareas administrativas, propagandísticas y misioneras en otros países (principalmente España, pero no solo). La revuelta de los memorialistas es una consecuencia de este exilio, y hace referencia al período durante el cual un grupo de jesuitas españoles descontentos con esta nueva situación escribió una serie de memoriales dirigidos a la Corte de Felipe II criticando el gobierno del General de la Compañía (tanto Mercuriano como, después, Aquaviva) y proponiendo una escisión que dotara a las provincias jesuitas españolas de un gobierno autónomo e independiente de Roma. Como veremos, este episodio compone el trasfondo sobre el que se dibuja la cuestión de la aceptación de los estatutos. 
cuestión de la procedencia judía. Esto sucederá sobre todo a partir de 1584, cuando Aquaviva mandará una serie de instrucciones a los provinciales de España sobre la «moderación açerca del reçebir gente que tenga raça», ordenando además destituir a todos los conversos que ocupen cargos importantes de gobierno, sobre todo en los territorios donde hubiera Inquisición ${ }^{14}$.

Vamos a reseñar la oposición de Pedro de Ribadeneyra ${ }^{15}$ a esta política, que consideraba contraria al mismo espíritu fundacional de la Compañía de Jesús. Ribadeneyra (1527-1611) había nacido en Toledo con el nombre de Pedro Ortiz y descendía de una familia conversa ${ }^{16}$. Trasladado a Italia, ingresó en la Compañía a los trece años de la mano del mismo Ignacio de Loyola, con quien trabó una estrecha y profunda relación, hasta el punto de considerarle su «segundo padre». Desempeñó cargos diplomáticos en Bruselas, ante la corte de Felipe II, y en Inglaterra, durante el reinado de María Tudor. También ocupó importantes cargos de responsabilidad al interno de la Compañía, como provincial superior de la Toscana y de Sicilia, rector del Colegio Romano o asistente para las provincias de España y Portugal.

La elección de Everardo Mercuriano como General en 1573 señala el inicio de una nueva política que alejará a numerosos jesuitas españoles de los cargos de poder. Ribadeneyra no es una excepción: al año siguiente será enviado a España, donde permanecerá en contacto con figuras importantes de la política y la espiritualidad castellana, y se dedicará a la redacción de su obra literaria, que comprende biografías de jesuitas, obras pías, historiográficas, políticas y de carácter propagandístico, además de traducciones de San Agustín.

14 Cfr. C. O'NEILL Y J. M. DOMÍNGUEZ (eds.), Diccionario Histórico de la Compañia de Jesús, t. II, 1003. 15 Adoptaremos esta grafía para el apellido, si bien otros autores le llaman «Rivadeneira» o «Rivadeneyra». La única biografía de este autor la escribió hace siglo y medio el padre jesuita J.-M. PRAT, Histoire du pere Ribadeneyra disciple de Saint Ignace. París, Victor Palmé, 1862, y bien merece una actualización. En España V. DE LA FUENTE le dedicó un florido relato biográfico en sus Obras escogidas del Padre Pedro de Rivadeneira de la Compañia de Jesús, con una noticia de su vida y juicio crítico de sus escritos, Biblioteca de Autores Españoles, vol. 60. Madrid, Imprenta de los Sucesores de Hernando, 1910 (ed. original de 1868). Las notas biográficas escritas en este siglo son escasas: merece la pena consultar el capítulo que le dedica R. Bireley en The Counter-Reformation Prince. Anti-Machiavellianism or Catholic Statecraft in Early Modern Europe. Chapel Hill and London, The University of North Carolina Press, 1990 y, en lo que respecta a su tratadística política, R. W. TRUMAN, Spanish treatises on government, society, and religion in the time of Philip II: the 'De regimine principum' and associated traditions. Leiden-Boston-Köln, Brill, 1999. Pueden hallarse más datos biográficos interesantes en el ya citado Diccionario Histórico de la Compañia de Jesús y, especialmente, en R. A. MARYKS, The Jesuit Order as a Synagogue of Jews. Jesuits of Jewish Ancestry and Purity-of-Blood laws in the Early Society of Jesus. Brill, Leiden-Boston, 2009.

16 Cfr. R.A. MARYKS, The Jesuit Order as a Synagogue of Jews, 42. 
La política anticonversa de Everardo Mercuriano al frente de la Compañía se vio continuada por su sucesor, Claudio Aquaviva, quien en 1593 decidió que la quinta Congregación General de la Compañía discutiría la posibilidad de establecer los estatutos de pureza de sangre en los Colegios de las provincias españolas. En un extenso memorial dirigido a Aquaviva, titulado De prognatis genere hebraerorum societatis aditu non excludendis, un ya anciano Ribadeneyra le expone al General trece motivos por los que no deberían aplicarse los estatutos ${ }^{17}$. En primer lugar, alega Ribadeneyra que las Constituciones de la Compañía no contemplan en ningún lado la discriminación de los conversos. Acto seguido Ribadeneyra testimonia de primera mano la aversión tanto de Loyola como de los siguientes Generales de la Compañía a la imposición de restricciones de genere. De Loyola, por ejemplo, dice nuestro autor que «yo le oý decir delante de muchos y con lágrimas en los ojos, y desde aquel tiempo lo tengo notado como cosa rara, y que nos causó admiraçión, que huuiera tenido por gran merced de Dios el auer nascido de judíos»; la causa la conocemos: «jcómo! poder ser pariente de Cristo nuestro Redemptor según la carne, y de la gloriosa Virgen María nuestra Señora!». Por este motivo Loyola, que «muchas uezes fué inportunado açerca desto del Padre Araoz, y siempre respondió que no era conforme al spíritu de Dios ni cosa que conuenía a la Compañía ${ }^{18}$.

Por Ribadeneyra también conocemos la oposición de Diego Laínez, segundo General de la Compañía, a las pretensiones continuamente avanzadas por Araoz de aceptar los estatutos. En una carta del 23 de Noviembre de 1564 Laínez establece, en cuanto a la discriminación de los conversos, una irónica distinción:

quanto al açeptar personas con nota, por acá no se aceptan personas que tengan nota según la ley de Dios o canónica; en las que tienen nota según las imaginaçiones, pareçe que basta guardarse o moderarse en las tierras donde reynan los tales humores 'ad duriciam cordis eorum'; donde no reynan, no ay para que impedir el bien de los que entran, y de los que son por ellos ayudados, pues 'in omni gente qui timet Deum, et operatur iustitiam, acceptus est Domino', y conforme a esto por acá se proçede, y creo nuestro Señor se sirue dello ${ }^{19}$.

17 El memorial puede leerse en P. Petri de Ribadeneira. Confessiones, Epistolae aliaque scripta inedita, t. II. Roma, M.H.S.I. (v. 60), 1969, 374-384.

18 P. Petri de Ribadeneira, 374-375.

19 Contra esta distinción de Laínez, que invita a «moderarse» sólo en las tierras donde reina la obsesión por la pureza de sangre (esto es, en la península), la quinta Congregación General impondría los estatutos de pureza de sangre de manera universal. 
El cuarto motivo expuesto por Riabadeneyra se basa en un episodio que le habría relatado Francisco de Borja, tercer General de la Compañía. Éste, ante las quejas del príncipe de Éboli, Ruy Gómez de Silva, por la admisión de conversos en los Colegios de la Compañía, le habría respondido aludiendo al poco caso que el mismo Felipe II habría hecho de estas cuestiones:

¿Cómo el rey tiene en su seruiçio a fulano y a fulano, que son deste linage? Pues su Majestad no mira esso en los que admite a su seruiçio, y mete en su casa; ¿queréis vos que lo mire yo para admitirlos en la casa de Dios y al seruiçio de aquel Señor, apud quem non est acceptio personarum neque distinctio indaei et graeci, neque barbarus neque scytha? ${ }^{20}$.

No vamos a ilustrar los trece argumentos de Ribadeneyra. Basten, para nuestros propósitos, estos ilustres testimonios aportados por el jesuita para resumir su sentir respecto la imposición de los estatutos. En pocas palabras, se podría decir que para Ribadeneyra el establecimiento de los estatutos de limpieza de sangre atenta contra la esencia misma de la Compañía, cifrada en la unidad de todos sus miembros para el fin común de la extensión del catolicismo contra las herejías que perseveran en Europa. Para cumplir su misión fundacional de extender el catolicismo la Compañía ha de ser un solo cuerpo, alma y corazón:

si pretendemos vnir la Compañía y soldar nuestrar quiebras y apagar este inçendio que el demonio ha leuantado [en referencia a las guerras de religión europeas], ¿pensamos que será buen medio el desunirla y despedaçarla más, y hazer que no aya hermano que mire con buenos ojos a su hermano, sino como a enemigo y como a hombre de otra casta y secta?.

Establecer este tipo de distinciones es, en definitiva, «contrario a la honra», la costumbre y el espíritu de la Compañía, como el mismo Gaspar de Quiroga, arzobispo de Toledo e Inquisidor General, habría admitido, «y otras persona graues lo han aprouado, por lo que nos inporta el ser todos cor unum et anima una» ${ }^{21}$.

El razonamiento de Ribadeneyra, sin embargo, no obtuvo los resultados esperados:

20 P. Petri de Ribadeneira, 377.

21 P. Petri de Ribadeneira, 380-82. 
Aquaviva hizo oídos sordos a la extensa argumentación de nuestro jesuita y la quinta Congregación General de la Compañía, celebrada entre noviembre de 1593 y enero de 1594, estableció la obligatoriedad de imponer los estatutos de limpieza para el ingreso en los Colegios jesuitas españoles.

4. Así pues, vemos que un jesuita español rechaza firmemente los estatutos de limpieza de sangre, con el beneplácito del Inquisidor General Quiroga, mientras que es el General italiano de la Compañía quien fuerza su imposición. Esta situación despierta varias preguntas -¿por qué el Inquisidor General rechaza los estatutos? ¿dónde radica el interés de Aquaviva por su aplicación?- cuya contestación requiere un breve ejercicio de contextualización.

El cardenal Quiroga, a diferencia de otros inquisidores más expeditivos como sus antecesores Fernando Valdés o Diego de Espinosa, no sentía una especial animadversión hacia los conversos. Era amigo personal de jesuitas como Ribadeneyra, a quien no dudaba en consultar incluso asuntos relacionados con su práctica institucional ${ }^{22}$, y fue, además, quien liberó a Fray Luís de León de la cárcel. Por otra parte, el mismo Ribadeneyra, como Laínez y otros muchos jesuitas españoles de renombre, era de ascendencia conversa, lo que en buena parte explica su oposición a la imposición de los estatutos. La ascendencia conversa de muchos de los primeros jesuitas es un hecho que no ha sido tenido en cuenta hasta fecha reciente a la hora de tratar su historia, lo cual se antoja un error dado que, como veremos, el «factor converso» podría ser una pieza para entender plenamente la situación creada en torno a la Quinta Congregación General jesuita y, más concretamente, las motivaciones que llevaron a Aquaviva a aplicar los estatutos.

Por su parte, entre los motivos que llevaron al General jesuita a aplicar los estatutos de pureza de sangre se ha aducido su voluntad de conciliación con Felipe II, una vez superada la «crisis de los memorialistas» que tuvo enfrentada a la Compañía con el monarca español durante varios años ${ }^{23}$. Sin embargo, nuevos datos dan pie a una

22 Cfr. su correspondencia epistolar en P. Petri de Ribadeneira.

23 Cfr. R. GARCÍA CÁRCEL, «La crisis de la Compañía de Jesús en los últimos años del reinado de Felipe II (1585-1598)», en L. A. RIBOT (coord.), La monarquía de Felipe II a debate. Madrid, Sociedad Estatal para la Conmemoración de los Centenarios de Felipe II y Carlos V, 395; J. MARTÍNEZ MILLÁN, «Transformación y crisis de la Compañía de Jesús (1578-1594)», en F. RURALE (ed.), I religiosi a corte. Teologia, politica e diplomazia in antico regime. Roma, Bulzoni, 127 y ss., si bien lo que realmente preocupaba a Felipe no era tanto la presencia de conversos en la Compañía cuanto lo que 
interpretación alternativa de este episodio. Así, Robert A. Maryks ha señalado, en un reciente estudio, la pretensión de los Generales Mercuriano y Aquaviva de «limpiar» los puestos de responsabilidad de la Compañía de jesuitas de ascendencia conversa -Maryks habla de una estrategia de «house cleansing». Esta estrategia se habría llevado a cabo a instancias de un «lobby anti-converso» cuyo vértice se hallaría en el mismo Papa Gregorio XIII, quien presionó para que fuera Mercuriano el elegido como cuarto General de la Compañía en lugar de Juan Alfonso de Polanco, el secretario personal de Ignacio «manchado» por su ascendencia conversa. Tras esta elección la estrategia de «house cleansing» habría conllevado el exilio de los puestos de poder de la Compañía en Italia de jesuitas prominentes, como es el caso de Juan de Mariana, Pedro de Ribadeneyra o Dionisio Vázquez, quienes fueron enviados de nuevo a España debido a su «nota» judía. Otros jesuitas notables, como Polanco y Jerónimo Nadal, fueron enviados a Sicilia y Austria, respectivamente. Les seguirían Baltasar Piñas, Manuel de Sá, Alfonso Salmerón y Gaspar de Loarte, entre otros ${ }^{24}$.

Esta «expulsión» o «exilio» al que se vieron forzados los jesuitas conversos no estuvo carente de consecuencias. Maryks señala, en este sentido, que no cree casual que entre el grupo de memorialistas que agitaron la revuelta contra los dirigentes de la Compañía se hallen jesuitas conversos como Mariana o Vázquez. Su intención era la de crear una Compañía con dos cabezas, teniendo, de este modo, los jesuitas conversos cabida y puestos de responsabilidad en la cabeza española. Apaciguada la revuelta y descabezado el proyecto de una Compañía de Jesús exclusivamente española, Aquaviva habría tomado represalias contra estos jesuitas conversos, que tantos quebraderos de cabeza le habían dado, aplicando los estatutos de pureza de sangre al interno de la Compañía. Así, para Maryks la imposición de los estatutos de limpieza de sangre en la Quinta Congregación General «was orchestrated as a punishment for the alleged participation of conversos in the revolt against the way in which Acquaviva and his assistants governed the Society» 25 .

Todo esto, ciertamente, no son más que indicios que permitirían sustentar una hipótesis sobre las motivaciones de Aquaviva distinta de la expuesta hasta ahora por los

esto presuponía: la presencia en sus reinos de una orden poderosa e influyente que escapaba a su control.

24 Cfr. R.A. MARYKS, The Jesuit Order as a Synagogue of Jews, 123.

25 R.A. MARYKS, The Jesuit Order as a Synagogue of Jews, 141. 
estudiosos españoles citados. Sin embargo, como el mismo Maryks admite, todavía se debe determinar si y en qué medida la participación de nuevos cristianos en la revuelta de los memorialistas confirió a la misma un carácter marcadamente pro-converso. Se hace necesario, por tanto, reexaminar el entero «episodio memorialista» a la luz de esta nueva línea de investigación.

5. La hipótesis de Maryks, sin embargo, ayudaría a iluminar y entender un poco mejor las motivaciones de Pedro de Ribadeneyra a la hora de oponerse a la imposición de los estatutos en la Compañía. Éste nunca participó de la revuelta de los memorialistas: al contrario, su posición fue siempre la de oponerse a un descabezamiento que no podía más que contradecir los designios de Loyola de que la Compañía actuara siempre con «una sola alma y un corazón». En este sentido, nuestro jesuita siempre observó fidelidad a las disposiciones que llegaban desde el vértice italiano de la Compañía, a pesar de sus reticencias y su estrecha amistad con otros jesuitas que sí participaron de la revuelta, como por ejemplo Juan de Mariana.

Aún así, el tema de la aceptación de los estatutos de pureza de sangre es tan importante para Ribadeneyra que le lleva a rayar la insubordinación e incluso amenazar al máximo dirigente de la Compañía y, como tal, sucesor de Loyola. En 1597 el toledano envía una carta a Aquaviva en la que insiste sobre la inconveniencia de la resolución adoptada tres años antes a favor de la aplicación de los estatutos en los Colegios jesuitas. A raíz de una congregación provincial celebrada en Toledo, en la que se había discutido el asunto, Ribadeneyra pone en boca de otros jesuitas una larga lista de motivos por los que se deberían derogar los estatutos, entre los que se encuentran los ya expuestos en su memorial de cuatro años antes ${ }^{26}$. En su propio nombre alega el que parece ser el argumento definitivo: ser el decreto contrario al «espíritu, juicio y sentimiento de nuestro santo Padre Ignacio», hasta tal punto que «temo no ha de reconoçer ny tener por hijos a todos los que anduuieron en él y persuadieron a los otros que se estableciesse, ni a los que,

26 También expone nuevos argumentos, como «que parece cosa duríssima que se puedan recebir y se reciben en la Compañía hios de padres hereges y aun los mismos hereges, como se reciben, y que no aya prohibición para ellos y que la aya para el que agora 300 años tuuo un agüelo moro o judío, aunque después acá todos sus descendientes ayan biuido como buenos cristianos» (P. Petri de Ribadeneira, 191). ¿Una crítica velada a la nueva política de admisiones de la Compañía? 
sabiendo y creyendo esto y pudiendo, no lo remedian» ${ }^{27}$. La suavidad de la forma en que se hace esta observación contiene, en realidad, una dura crítica no sólo a los jesuitas que favorecen la aplicación de los estatutos, sino a la Compañía por entero, puesto que Ribadeneyra acusa de malos jesuitas no sólo a los promotores del establecimiento de los estatutos, o a los que se persuadieron de su conveniencia, sino también a los indiferentes que pudiendo no hicieron nada por evitar su aplicación (y seguían sin hacerlo). Todos los jesuitas que acepten los estatutos, aunque sea a regañadientes, son culpables ante los ojos de Ignacio a menos que se rebelen (no, ciertamente, a la manera de los memorialistas, que Ribadeneyra no aprobaba, pero sí, suponemos, de otras maneras menos expeditivas).

Es por este motivo que Ribadeneyra se siente obligado a reiterar su disgusto hacia los estatutos y pedir su anulación: quien los aplica o consiente su aplicación no puede ser un buen jesuita. Siguiendo esta lógica el toledano debería llegar a la conclusión de que toda la Compañía está traicionando el espíritu del padre fundador de manera consciente. Para evitar esto el jesuita concluye su misiva suponiendo que el memorial anterior «temo que o no llegó, o no se leyó, o no huuo tiempo para considerar las razones que en él dezía» ${ }^{28}$, único motivo que explicaría la continuidad de la aplicación de los estatutos a pesar de la evidencia de resultar éstos contrarios a la voluntad de Ignacio. No podemos saber hasta qué punto se trata de una suposición hecha sinceramente.

Las muestras de rechazo no acaban aquí. Todavía en Enero de 1608 un Ribadeneyra cercano a la muerte escribe a Aquaviva sobre la cuestión, en vista de la sexta Congregación General de la Compañía que estaba a punto de celebrarse (iniciaría el 21 de febrero): esta vez le pide expresamente que se anule «el decreto de génere que se hizo en la congregación general passada, y se guardasse lo que ordenan nuestras Constituciones». De nuevo le expone los motivos de las anteriores misivas, si bien ahora Ribadeneyra establece una excepción en lo que respecta a la provincia de Portugal, cuyos padres «hallarán dificultad en deshacer el decreto; porque quizá a su prouincia conuiene guardarle; mas yo juzgo que se puede guardar, si conuiene, sin decreto, por prouidencia y orden del general». ¿Se trata de una concesión debida a la mayor presencia de criptojudíos en tierras lusas? Aún así la conclusión no cambia: el decreto es abominable y contrario al

27 P. Petri de Ribadeneira, 192.

28 P. Petri de Ribadeneira, 193. Por esta carta averiguamos que nuestro jesuita no recibió ninguna respuesta al envío de su memorial anterior. 
espíritu de Ignacio, hasta tal punto que Ribadeneyra aconseja a Aquaviva que mire y procure, «quando Dios le llamare para sí», que «el Padre [Loyola] le reconozca por uerdadero hijo y zeloso conseruador de su espíritu: que por saber yo tanto de lo que sentía en esto, y tenerlo notado y escrito más ha de 44 años, y creer que su santa alma lo dessea más que su canonización, lo digo desta manera» ${ }^{29}$.

La advertencia de Ribadeneyra cela un tono amenazante que concierne, esta vez, a la integridad espiritual del mismísimo General de la Compañía en el más allá. Si en la anterior misiva todos los miembros de la Compañía corrían el riesgo de desmerecer como jesuitas a ojos del padre fundador, en ésta es el alma del propio General la que corre el riesgo de no ser reconocida por él como «verdadero hijo»y «conservador de su espíritu»función, esta última, esencial para el cargo de General de la Compañía. Esta vez las «advertencias» de Ribadeneyra apuntan más alto: si antes acusaba a todos los jesuitas de ser cómplices (con lo que la generalidad del objeto de acusación diluía el alcance de la amenaza), ahora el principal culpable de la situación es uno solo, Aquaviva, y la amenaza resulta tan clara como contundente. El velado atrevimiento de un Ribadeneyra cercano a la muerte -le quedaban tres años de vida- revela, de nuevo, la importancia que la cuestión conversa revestía para él. Su interpretación del espíritu y las intenciones de Ignacio de Loyola, que son a su vez el espíritu y las intenciones de la Compañía, constituye el principal argumento de su profunda aversión a los estatutos de pureza de sangre. Esta interpretación reviste, además, una especial importancia, dado que en 1608 Ribadeneyra se encuentra entre los últimos jesuitas que conocieron personalmente al fundador de la Compañía. Se da también la circunstancia de que, como hemos señalado, Ribadeneyra tuvo con Ignacio una especial intimidad y es, además, el autor de su primera biografía «oficial»-lo que tiene «notado y escrito más ha de 44 años». Por este motivo nuestro jesuita podía afirmar «saber yo tanto de lo que [Loyola] sentía en esto». Así pues, si bien Ribadeneyra se encuentra «exiliado» en Madrid, lejos de cualquier responsabilidad administrativo o ejecutiva, su autoridad a la hora de hablar del sentir y el parecer del fundador de la Compañía debía ser mayor que la de cualquier otro jesuita, y el peso de sus palabras se debía hacer sentir de manera especial en los oídos y las mentes de sus interlocutores.

Ribadeneyra no fue el único que se opuso a la imposición de los estatutos de 
pureza de sangre. Prominentes jesuitas españoles e italianos como Antonio Possevino, Juan de Mariana, Diego de Guzmán y García Girón de Alarcón desarrollaron, tras la quinta Congregación General, una firme oposición a dicha norma. Sin embargo, sus esfuerzos tuvieron un magro resultado: la sexta Congregación General jesuita, celebrada en 1608 y presidida por Aquaviva, se limitó a circunscribir el examen de pureza de sangre hasta la quinta generación ${ }^{30}$.

6. Ahora bien, siendo Ribadeneyra un cristiano nuevo, su defensa de los jesuitas de origen converso y su ataque a los estatutos de pureza de sangre no deben hacernos pensar que no comulgara con la unificación religiosa y la homogeneización confesional promulgada por los Reyes Católicos. Si Loyola había deseado ser él mismo judío, Ribadeneyra, por contra, alaba con entusiasmo la decisión de Isabel y Fernando de expulsarlos de la península en su Tratado de la religión y virtudes que debe tener el príncipe cristiano (1595) ${ }^{31}$. ¿Cómo es esto posible? La actitud de Ribadeneyra hacia los conversos y descendientes de judíos no debe confundirse con su actitud hacia los propios judíos. Los primeros, entre los que se cuenta el propio autor, han de ser bienvenidos en la Compañía y deben formar una parte importante de la misma. Los judíos, por contra, son siempre una secta que, perseverando en el error, mancha la pureza religiosa que debe imperar en España. Es por este motivo que Ribadeneyra alaba la decisión de los Reyes Católicos de expulsarlos de España, pues así los reyes «tuvieron más en cuenta con conservar y amplificar en ellos [los reinos de España] la pureza de nuestra santa religión, que no con la rentas reales, que saliendo de ellos [los judíos], necesariamente se habían de menoscabar y disminuir». Este servicio a Dios hecho de manera desinteresada por parte de Isabel y Fernando se vio recompensado con creces, pues

el mismo Dios aventajadamente se le pagó, limpiando estos reinos de toda fealdad e inmundicia de falsas sectas, y conservándolos hasta ahora en la entereza y puridad de la fe católica, y en justicia y en paz, y dándoles otros reinos, y descubriendo por su mano un nuevo mundo, con tantos y tan grandes tesoros y riquezas, que es uno de los mayores

30 Cfr. R.A. MARYKS, The Jesuit Order as a Synagogue of Jens, 159.

31 El título completo de la obra es Tratado de la religión y virtudes que debe tener el príncipe cristiano para gobernary conservar sus estados, contra lo que Nicolás Maquiavelo y los políticos deste tiempo enseñan, incluido en V. DE LA FUENTE (ed.), Obras escogidas del Padre Pedro de Rivadeneira, 419-587. 
milagros que ha habido en él ${ }^{32}$.

Nada menos que el descubrimiento de América habría sido un «premio» concedido por la Providencia divina a los monarcas merced a la expulsión de los judíos (o, si se prefiere, una compensación, dadas las pérdidas económicas que supuestamente acarreaba la expulsión). No es casual, desde esta clave de lectura histórica, que tanto la expulsión como la toma de Granada sucedieran el mismo año del descubrimiento.

Por opuestas que sean, las posiciones de Ribadeneyra ante judíos y conversos proceden, en el fondo, de una misma creencia: en el carácter providencial de la historia, cuyo fin último es la extensión del catolicismo en todo el orbe. El ideal de la extensión del catolicismo, encomendada por Dios a la Compañía, requiere la inclusión de los conversos dentro de una comunidad cristiana activa y militante en todo el mundo. Por otra parte, ese mismo ideal justifica y legitima la expulsión de los judíos, en la medida en que supone un paso más dentro de su ejecución. Lo prueba, como argumenta Ribadeneyra, la recompensa divina recibida por los Reyes Católicos.

De este modo, el episodio de la expulsión de los judíos se inserta dentro de la lectura providencial de la historia de España que Ribadeneyra hace en el Tratado del Príncipe Cristiano, y que supone el fundamento último de su doctrina política. En la historiografía de nuestro jesuita encuentran cabida los principales protagonistas de la historia peninsular reciente y no tanto: desde don Ramiro hasta Enrique IV, pasando por Fernando el Magno, Alfonso el Casto o Fernando el Santo, todos encarnan, por el carácter confesional de su política, ejemplos a seguir de monarcas cristianos ${ }^{33}$. Pero más allá de su ejemplaridad, suponen también estadios precedentes de la historia española, que tiende por voluntad de Dios hacia el fin último de la extensión universal del cristianismo. Por este motivo su ejemplaridad radica, principalmente, en su lucha contra los musulmanes y el papel que desempeñaron a la hora de hacer avanzar la Reconquista cristiana de la península, de la misma manera que la ejemplaridad de los Reyes Católicos radica en la expulsión de los judíos. Todos forman una línea temporal recta que apunta, inevitablemente, hacia ese fin último de la historia desde el que Ribadeneyra lee el pasado español, y en virtud del cual se justifica la necesidad de «que los príncipes se gobiernen por la ley de Dios, más que por la 
falsa razón de estado», que es el título del capítulo en el que el jesuita toledano alaba la expulsión de los judíos.

7. Las diferencias existentes entre el espíritu que anima a la entera Compañía y su peculiar «modo de proceder», por un lado, y la realidad socio-política castellana, representada por la Inquisición y los estatutos de pureza de sangre, por otro, se hacen patentes en la forma de actuar de ambas instituciones, pero no en el fondo ideológico sobre el que se inscribe dicha forma de actuar. Creo que tanto la Inquisición como la Compañía (durante sus inicios fundacionales), deben entenderse dentro de los parámetros ideológicos propios de la cultura castellana instituida por la ideología de la Reconquista establecida por los Reyes Católicos, pues beben de los ideales religiosos, políticos y militares propios de dicha época y que impregnarían la España de los siglos XVI y XVII.

Ciertamente, la Compañía de Jesús y la Inquisición encarnan, durante la segunda mitad del s. XVI, dos concepciones opuestas de la comunidad cristiana, de su composición y su finalidad terrena: exclusiva y particular en el caso de la Inquisición, inclusiva y universal en el de la Compañía. El Inquisidor pretende preservar la pureza de sangre y de pensamiento de la comunidad cristiana mediante el control y la persecución de los individuos, realizando así una purga de conciencia al interno de la península y estableciendo un cordón sanitario que mantenga alejadas las ideas heréticas que recorren el resto de Europa; el jesuita, por contra, quiere extender los límites de la comunidad cristiana a todo el orbe mediante la enseñanza, la predicación, y la formación de las conciencias. Su ideal de conversión, lejos de mantener a la península aislada de las ideas erróneas, pretende conocerlas a fondo para mejor persuadir los ánimos y las conciencias herejes e infieles. Lejos de excluir a nadie, el ideal que le mueve promueve la aceptación en el seno de la comunidad cristiana de gente de todas las procedencias y «calidades», instando además a la convivencia con «el otro», a conocerle mejor para, mediante la adaptación a su estilo de vida y sus categorías mentales, conseguir su conversión. Exclusión, aislamiento y preservación de la pureza por un lado; inclusión, extensión de la fe y acercamiento a los «impuros» para su conversión por el otro.

Son éstas dos concepciones de la comunidad cristiana que no por ser diametralmente opuestas dejan de tener idénticas raíces castellanas. Entenderlas sólo por oposición sería, a mi entender, caer en una visión reduccionista de la cultura política y 
religiosa castellana. Cierto que se oponen, pero también se pueden hallar puntos de unión: la Inquisición española surge, como institución orgánicamente ligada a la monarquía española, por voluntad de los Reyes Católicos. Por su parte, el ideal religioso de Loyola surge en contacto con corrientes espirituales conversas propias de una cultura religiosa castellana que presenta, en algunos aspectos, rasgos comunes con los ideales establecidos por Isabel y Fernando. Se ha hablado de interioridad espiritual, pero hay también, en este ambiente, un espíritu de misión, cruzada y extensión universal del cristianismo que hallamos tanto en Loyola como en el ideal de extensión de la Reconquista legado por el testamento de Isabel la Católica. El mismo fundador de la Sociedad, antiguo soldado, se ve a sí mismo a través del cristal del ideal caballeresco dirigido «a lo divino» ${ }^{34}$, mientras que Ribadeneyra, por su parte, no dudará en su Tratado del príncipe cristiano en justificar la guerra de religión y defender, contra Maquiavelo, la mayor aptitud de los cristianos para tomar las armas.

A pesar de sus diferencias, ambas concepciones de la comunidad cristiana surgen de un estrato cultural común, que es el que se configura durante el reinado de los Reyes Católicos y cuenta a la creación de la Inquisición, la conquista de Granada, la extensión de la Reconquista hacia el norte de África y la expulsión de los judíos entre sus hitos más significativos -al menos en el plano de las realizaciones políticas. Es la época en que el catolicismo, promulgado como la única religión del estado, ejerce un rol vertebrador y aglutinador de la sociedad castellana, que se traduce en la paulatina exclusión del resto de confesiones y en el control social ejercido por la Inquisición, pero también en las esperanzas de tipo mesiánico y la vocación misionera que encontramos en el joven Loyola ${ }^{35}$.

\footnotetext{
34 Sobre este tema cfr. J. CARO-BAROJA, «Fantasías y lucubraciones en torno a San Ignacio de Loyola y su Compañía», en ID. (ed.), Ignacio de Loyola, magister artium en París 1528-1535. San Sebastían, KutxaCaja Gipuzkoa San Sebastián, 1991, 19-26; J. M. CACHO BLECUA, «Del gentilhombre mundano al caballero 'a lo divino': los ideales caballerescos de Ignacio de Loyola», en J. PLAZAOLA (ed.), Ignacio de Loyola y su tiempo, 129-159.

35 Cfr. I, IANUZZI, «Mentalidad inquisitorial y jesuitas».
} 